OMAE2011-49399

\title{
FAECAL PELLETS IN DEEP MARINE SOFT CLAY CRUSTS: IMPLICATIONS FOR HOT-OIL PIPELINE DESIGN
}

\author{
Matthew Y-H. Kuo \\ Geomechanics Group \\ Department of Engineering \\ University of Cambridge \\ Cambridge, United Kingdom \\ Email: myhk2@cam.ac.uk
}

\author{
Malcolm D. Bolton \\ Geomechanics Group \\ Department of Engineering \\ University of Cambridge \\ Cambridge, United Kingdom \\ Email:mdb@eng.cam.ac.uk
}

\section{ABSTRACT}

In recent years, the presence of crusts within near surface sediments found in deep water locations off the west coast of Angola has been of interest to hot-oil pipeline designers. The origin for these crusts is considered to be of biological origin, based on the observation of thousands of faecal pellets in natural crust core samples. This paper presents the results of laboratory tests undertaken on natural and faecal pellet-only samples. These tests investigate the role faecal pellets play in modifying the gemechanical behaviour of clayey sediments. It is found that faecal pellets are able to significantly alter both the strength and the average grain-size of natural sediments, and therefore, influence the permeability and stiffness. Hot-oil pipelines self-embed into and subsequent shear on crusts containing faecal pellets. Being able to predict the time required for installed pipelines to consolidate the underlying sediment and thus, how soon after pipe-laying, the interface strength will develop is of great interest to pipeline designers. It is concluded from wet-sieving samples before and after oedometer tests, that the process of pipe laying is unlikely to destroy pellets. They will therefore, be a major constituent of the sediment subject to soil-pipeline shearing behaviour during axial pipe-walking and lateral buckling. Based on the presented results, a discussion highlighting the key implications for pipeline design is therefore provided.

\section{Introduction}

Deep ocean sediments off the West coast of Africa exhibit peculiar strength behaviour, which manifests itself as a crust (see Figure 1). Recent detailed investigation into their origin has highlighted the presence of abundant faecal pellets [1-3]. Hot-oil pipelines are installed into these crust sediments, and therefore, the soil characteristics is of key interest to pipeline designers. No previous research has explicitly investigated and identified the influence of faecal pellets on the geotechnical behaviour of natural sediments. This paper, thus presents unique data providing evidence for the significant influence faecal pellets have on the consolidation, permeability and stiffness characteristics of natural and laboratory-prepared samples.

\subsection{Background}

The influence of burrowing invertebrates in marine sediments has been documented by numerous authors ( [5], [6], [7], [8]). The main influence these organisms have on the sediment is through their daily feeding activities. By utilising the shallow marine sediments as their source of food, they gradually modify the sediment from 'unprocessed' to 'processed' material, thus imparting a biological structure on already naturally structured sediment.

\subsection{Influence on Sediment Shear Strength}

Early investigations suggest the presence of crust-like sediment strengths occurring in the Clyde Sea, Scotland $[9,10]$. Find- 


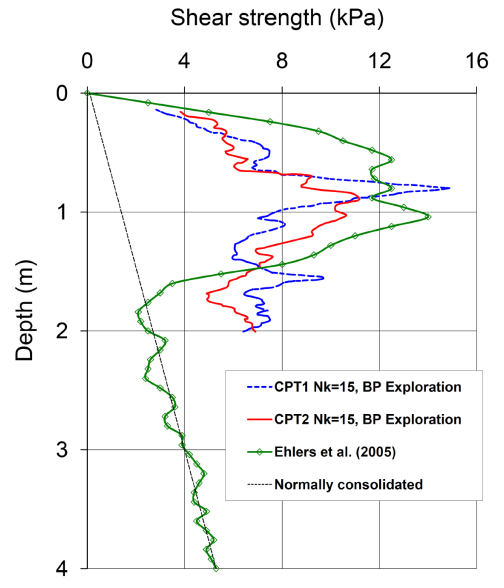

FIGURE 1: CPT profiles of undrained shear strength showing West African deep ocean sediment crusts, modified after [4].

ings indicated the presence of stiff to hard layer conditions at a depth of $20 \mathrm{~cm}$, which are comparable to the depth of increased strength observed in the West African crusts [9]. No explicit strength measurements were undertaken. In these same sediments, up to $40 \%$ of the sample by dry mass comprised of faecal pellets [10]. It was only suggested that the pellet's contribution to modification of the sediment properties was an increase in grain size and thus, porosity.

A detailed examination of invertebrate bioturbation in cores taken from the central Southern Pacific Ocean at ultra-deep water depths from $5,000 \mathrm{~m}$ to $5,300 \mathrm{~m}$ was undertaken [11]. Undrained shear strength was measured using a Geonor fall cone penetrometer at $0.05 \mathrm{~m}$ intervals down-core, which indicated local peak values of up to $12 \mathrm{kPa}$ at $0.4 \mathrm{~m}$ depth. Variations in strength were attributed to the effects of bioturbation, whereas the general increase in strength with depth was suggested to be the result of normal consolidation of the clay due to increasing vertical effective stress [7], although it should be evident that the strength associated with a normally consolidated clay (based on a submerged unit weight, $\gamma^{\prime}=2.5 \mathrm{kN} / \mathrm{m}^{3}$ ) is significantly lower than the measured strengths. An investigation into the relationship between peaks in strength and the number of burrows observed was inconclusive. Even when ignoring these localised peak strengths, the measured strength is least three times greater than the predicted normally consolidated strength profile. The authors of the current investigation suggest that the effects of bioturbation may influence the general strength profile, not just the localised fluctuations.

In situ cone penetration tests with pore pressure measurement (CPTU) data from the Nova Scotian Slope located on the eastern Canadian continental margin have been completed [12]. Using a sit-on-bottom CPT unit with $2 \mathrm{~m}$ penetration capability, strength and induced pore pressure measurements were un- dertaken. Sediments encountered comprised Holocene surficial clays, slumped sandy sediments of past debris flows and Pleistocene sediments of overconsolidated clays. Transect 'HMG 6' (approximately $1200 \mathrm{~m}$ in length) lies in between $1400 \mathrm{~m}$ and $1450 \mathrm{~m}$ water depth and corresponds to Holocene deposits with no material removed by prior erosional events. Using a cone factor, $N_{k}$ of 15 , derived shear strength values exhibited a dramatic strength increase to about $12 \mathrm{kPa}$ at $0.5 \mathrm{~m}$ depth before reducing to $3.5 \mathrm{kPa}$ at $1.5 \mathrm{~m}$ to $2.0 \mathrm{~m}$ depth. Crustal strength was observed to coincide with zoophycos-type burrows, however, the influence of burrows or otherwise is not explicitly presented.

An investigation into the feasibility of manganese nodule mining within the Peru Basin identified sharp increases in sediment strength at between $0.1 \mathrm{~m}$ and $0.15 \mathrm{~m}$ depth [13]. Strengths peaked at between $6 \mathrm{kPa}$ and $10 \mathrm{kPa}$ at $0.2 \mathrm{~m}$ depth. Based on $\mathrm{X}$-ray analysis of clay content, it was found that the sediments predominantly comprised of smectites. Different clay minerals (smectite, kaolin, illite and chlorite) were 'mixed' within the sediment profile and was attributed to the bioturbation of burrowing organisms [13]. In these final three investigations, no determination of the abundance of faecal pellets was made. All however, identify some influence of burrowing invertebrates through the evidence of open burrow systems within or near crust material.

\subsection{Influence on Permeability and Porosity}

The influence of permeability and porosity is considered by $[8,14-16]$. These investigations only consider the role of burrows, and again, no comment is made of the possible influence of faecal pellets on sediment permeability.

\subsection{Influence on Particle Size}

[17] observed an increase in mean particle size due to the "aggregation of fine particles into faecal pellets" ( [17], p1354). This was determined by dry-sieving sediment before and after the introduction of burrowing invertebrates. These observations are similar to those made of the abundance of faecal pellets in Scottish sediments [10]. Bioturbation of sediment by Arenicola $s p$. increases the average grain size at its preferred feeding depth of between 20 and 30 centimetres below the seabed level [6]. An increase in average particle size will have an influence on the strength and stiffness behaviour of the material, and on the manner in which it is interpreted by geotechnical engineers (drained versus undrained).

\subsection{Aims for Research}

The geotechnical behaviour of crust material is of interest to pipeline designers. In addition to the interface coefficient of friction and undrained shear strength, the permeability will dictate a pipeline's rate of consolidation during installation. The ability to accurately predict the time required to achieve pipline 
embedment levels will thus be improved. Furthermore, during axial shearing and lateral buckling, the soil permeability will govern whether the shearing behaviour proceeds in a drained or undrained matter. The previous belief that crust material solely comprises 'clay' may have caused misconceptions in the prediction of soil-pipeline behaviour, and has masked the need to undertake detailed examination of the natural structure of crust sediments. This paper therefore addresses these points by:

1. demonstrating that crust material comprises abundant faecal pellets;

2. presenting test data of natural and laboratory-prepared samples, which highlight the influence of faecal pellets; and

3. highlighting key points of discussion for the design of hotoil pipelines.

\section{Wet Sieving of Natural Samples}

Conventional particle size distribution (PSD) analysis of clayey soils based on ASTM D442-63 was found to be an inappropriate method for investigating the individual pellets found within these sediments due to the mechanical breakage of pellets during preparation. Pellet preservation was achieved by utilising the author's previous experience of techniques used in sedimentological washing of foraminifera. Using this method, bulk natural samples were carefully washed with running water through a series of sieves without prior drying, crushing or remoulding of the sediment. This process ensured the survival of preexisting biologically-bonded aggregates for post-washing analysis. The sieve sizes used included $465 \mu \mathrm{m}, 300 \mu \mathrm{m}, 212 \mu \mathrm{m}$, $125 \mu \mathrm{m}, 75 \mu \mathrm{m}, 63 \mu \mathrm{m}, 53 \mu \mathrm{m}, 38 \mu \mathrm{m}$, and $20 \mu \mathrm{m}$, with material passing the smallest sieve being discarded.

Samples were prepared by measuring the water content of cuttings adjacent to the test sample and prepared following [3]. The mass of sieved pellets was converted to a percentage of the unsieved material and values are herein quoted as the 'faecal pellet percentage'.

Several cores were wet-sieved at varying depths to determine faecal pellet percentages of material greater than $63 \mu \mathrm{m}$, shown in Figure 2. Figure 3 presents the percentage passing each sieve size for Core B shown in Figure 2. The sieve fraction percentages are typical for most cores tested, with the majority of pellets in the cores found in the $63 \mu \mathrm{m}$ to $125 \mu \mathrm{m}$ fraction, and the smallest percentage found in the $300 \mu \mathrm{m}$ fraction. Core $\mathrm{G}$ represents material containing a significantly high sand fraction. A typical example of a wet-sieved sample is shown in Figure 4.

\section{Oedometer Testing}

The observation that natural samples from below the crust contain only $15 \%$ faecal pellets by dry mass suggests that the process of geological burial (normal consolidation) plays a ma-

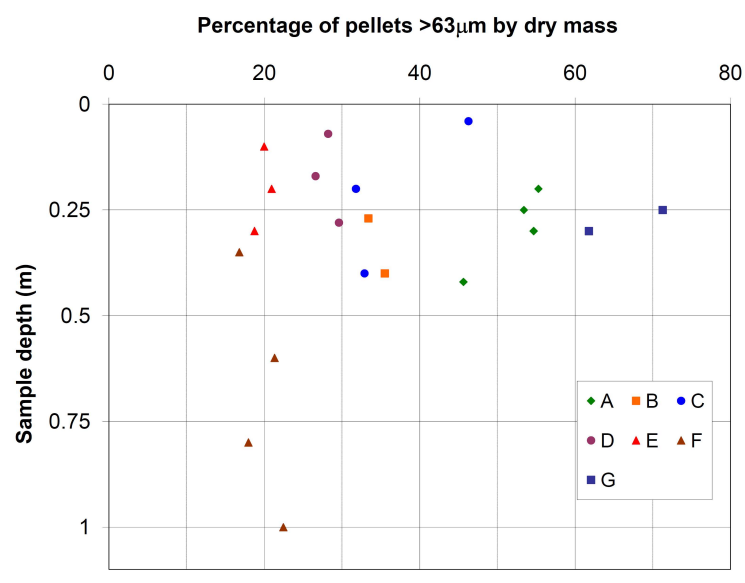

FIGURE 2: Faecal pellet percentages by dry mass for core samples of crust material.

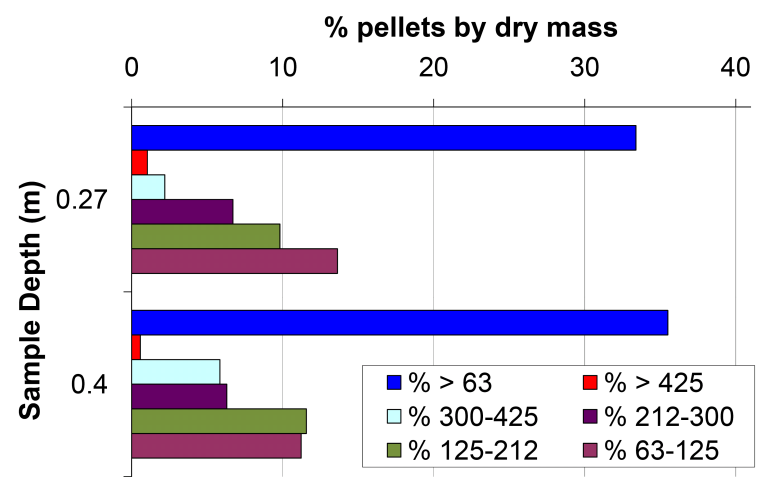

FIGURE 3: Percentage of faecal pellets remaining on each sieve fraction for Core B. Fractions are typical for most cores tested.

jor role in reducing pellet numbers. This correlates with the observation that the occurrence of a crust is related to the existence of high pellet percentages, the vertical extent of which is limited to a narrow range of depths in the near-surface seabed sediments. The demise of pellets due to crushing under overburden stress was one hypothesis for the loss of strength below the crust. Oedometer tests were therefore undertaken to investigate the behaviour of crust sediments under stresses exceeding their in situ stress state.

\subsection{Testing of Natural Samples}

The following objectives were considered during oedometer tests:

1. estimation of preconsolidation stresses of crust samples;

2. investigation of the compression and unloading behaviour at very low stresses and also at beyond the in situ vertical 
effective stress;

3. investigation of the change in physical properties during compression and potential loss of crustal strength; and

4. comparison with existing oedometer data from similar geographic locations, which considered samples taken from below the crust.

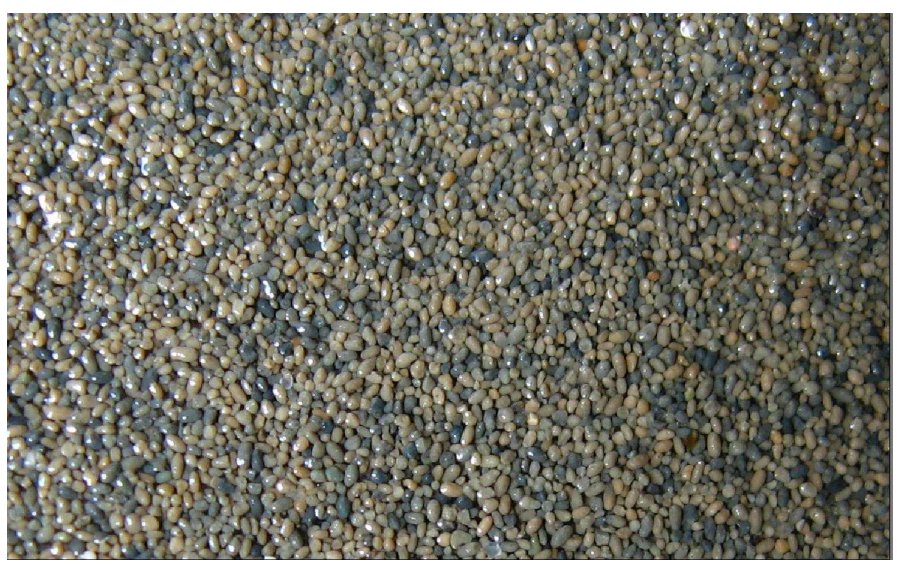

FIGURE 4: Typical wet-sieved faecal pellets of $212 \mu \mathrm{m}$ to $300 \mu \mathrm{m}$ diameter.

3.1.1 Sample Preparation A conventional rearloading oedometer apparatus was used to test crust samples from $0.25 \mathrm{~m}$ and $0.3 \mathrm{~m}$ depth. A stress range of $1 \mathrm{kPa}$ to $282 \mathrm{kPa}$ (corresponding to a sediment depth of $100 \mathrm{~m}$ ), doubling the load at each stage, was applied to the samples in order to investigate a range of stresses from below to well past the in situ vertical effective stress. Oedometer test samples were prepared using the procedure detailed in [3].

The samples were permitted to consolidate for at least 24 hours at each stage or until primary consolidation was completed. To investigate the small-stress consolidation behaviour of the West African clays at $0.03 \mathrm{~m}$ (above the crust), a low-friction, one-dimensional set-up was used comprising a light weight, selfhanging loading frame.

If the hypothesis that faecal pellet destruction is due to increasing vertical effective stress, the specific volume-vertical effective stress $\left(v-\sigma_{v}^{\prime}\right)$ relationship might have been expected to show the behaviour of a sensitive soil with large volume reduction at a preconsolidation stress, $\sigma_{c}^{\prime}$ of approximately $2.5 \mathrm{kPa}$, corresponding to the in situ effective stress near the bottom of the crust. Furthermore, the percentage of pellets at each sieve fraction before testing should be significantly higher than the percentage following the test.

\subsection{Faecal Pellet-Only Oedometer Tests}

To provide comparisons with natural samples containing different percentages of faecal pellets, a pellet-only oedometer sam- ple was prepared. This sample was created by sieving natural pellets of $125 \mu \mathrm{m}$ to $212 \mu \mathrm{m}$ diameter from bulk samples, and prepared by the procedure detailed in [3].

\section{Oedometer Testing Results}

Analysis and interpretation of the oedometer test results focused on the influence of faecal pellets. The sample containing pellets only was considered to be the upper bound of a series of pellet-sediment mixtures ranging from $100 \%$ pellets, through crust containing over $50 \%$ pellets to the non-crust sample containing less than $20 \%$ pellets. Initial water contents for these samples were $253 \%$ for the non-crust sample from $0.03 \mathrm{~m}$ depth, and $174 \%$ and $194 \%$ for crust samples from $0.25 \mathrm{~m}$ and $0.3 \mathrm{~m}$, respectively.

\subsection{One-Dimensional Stiffness}

The tangential one-dimensional stiffness, $E_{v}^{\prime}$ determined by averaging adjacent pairs of stiffness values calculated for each stress increment, is plotted against the cumulative applied vertical effective stress on log-log axes in Figure 5. The corresponding specific volume, $v-\sigma_{v}^{\prime}$ relationship on semi-log axes is shown in Figure 6.

Figure 5 indicates that the relationship between the natural clay samples' one-dimensional stiffness and cumulative applied vertical effective stress falls within a relatively well-defined band of values, where the relationship may be approximated by a power law. In contrast, the relationship for the pellets-only sample is more complex. It is initially observed that the tangential one-dimensional stiffness increases with cumulative applied stress to a maximum of about $22 \mathrm{MPa}$ at approximately $1.6 \mathrm{kPa}$ vertical stress (path 'A' shown in Figure 5), before reducing to a relatively consistent stiffness of $6.6 \mathrm{MPa}$ to $7.8 \mathrm{MPa}$ (paths ' $\mathrm{B}$ ' and ' $\mathrm{C}$ '). A 'collapse' in the structure and thus sudden drop in voids ratio corresponding to this rapid reduction in stiffness may have been expected. The reduction in stiffness to one third of the original value corresponds to a relatively large change in specific volume per stress increment in Figure 6. Lateral support for individual pellets will only be in the form of point contacts with adjacent pellets. Large, water-filled macro-voids will therefore be present initially. The reduction in stiffness may be due to the crushing of some pellets.

With a further increase in the vertical effective stress, it is observed that the tangential stiffness remains relatively constant (path ' $C$ '). This may be due to continual breakage of pellets and particle rearrangement with increasing stress, which does not permit the stiffness to increase. The stiffness behaviour of the pellets then approaches a trend similar to the natural samples containing $50 \%$ pellets (path ' $D$ '). Wet sieving of the pellet sample at the end of the pellet oedometer showed that $71 \%$ of pellets remained intact. $9 \%$ of the sieved material represented 


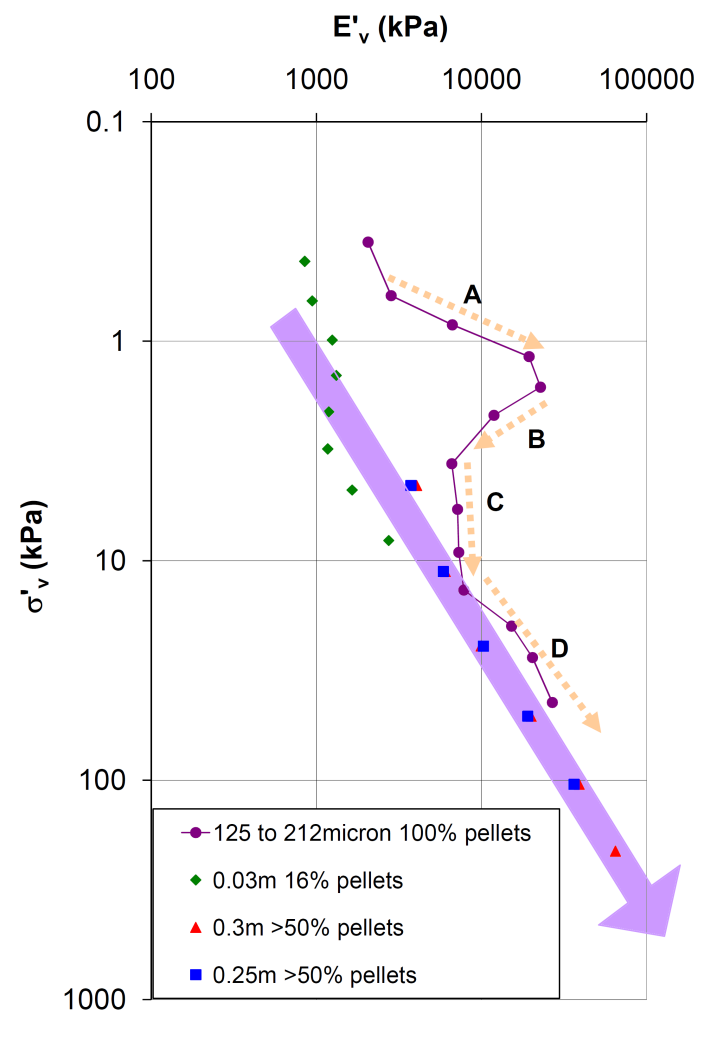

FIGURE 5: Tangential one-dimensional stiffness $E_{v}^{\prime}$ plotted against cumulative applied $\sigma_{v}^{\prime}$ for samples of only-pellet and natural samples from depths of $0.03 \mathrm{~m}, 0.25 \mathrm{~m}$ and $0.3 \mathrm{~m}$.

crushed pellet fragments sized between $63 \mu \mathrm{m}$ and $125 \mu \mathrm{m}$. The remaining $20 \%$ of material represented crushed fragments less than $63 \mu \mathrm{m}$. During consolidation, the crushed pellet material would progressively fill the macro-voids between intact pellets. The resulting mixture of pellet and pellet-fragment material will therefore approach the behaviour of a pellet-clay matrix typical of natural crust sediments.

Figure 6 also presents results obtained by [18] for samples taken from $4 \mathrm{~m}$ depth (below the crust). The following points on the relative compression behaviours are noted:

1. an apparent preconsolidation stress, $\sigma_{c}^{\prime}$ of $10 \mathrm{kPa}$ is suggested by crust material. Material above the crust exhibits $\sigma_{c}^{\prime}$ of $1 \mathrm{kPa}$, and material below the crust apparently has $\sigma_{c}^{\prime}=25 \mathrm{kPa}$.

2. once past $\sigma_{c}^{\prime}$, the slope of the curve defines the compression index, $c_{c}$, which is found to be 1.88 above the crust and between 1.01 and 1.22 within the crust. Below the crust at $4 \mathrm{~m}$ depth, data of [18] indicates that $c_{c}$ approaches the intrinsic compression line (ICL) defined by [19], with a value that is comparable to the crust;

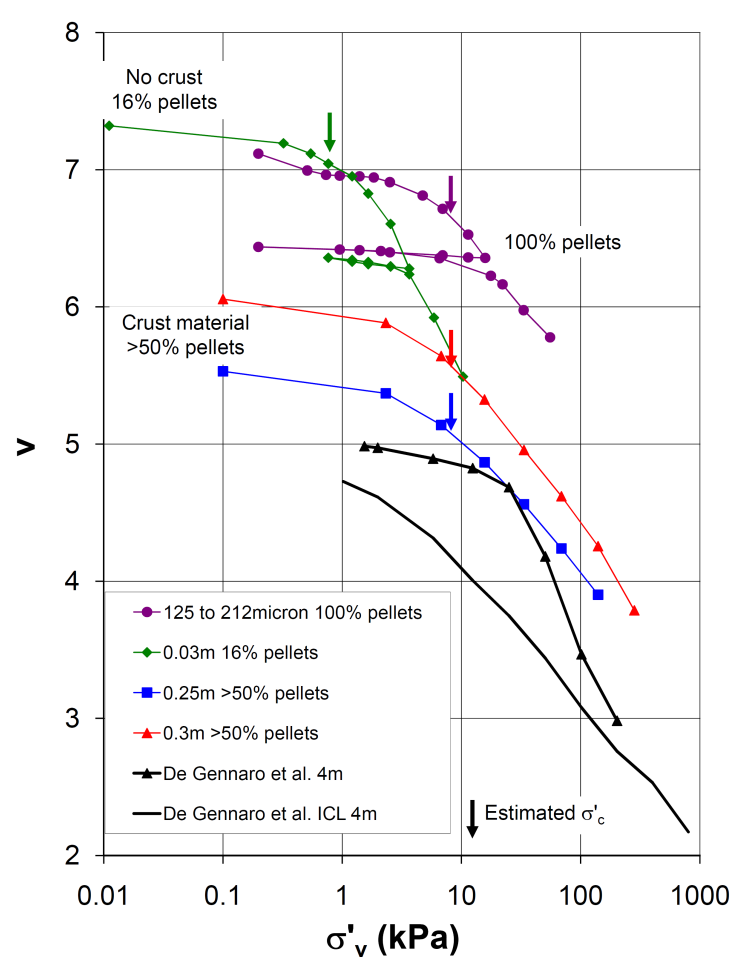

FIGURE 6: Specific volume plotted against the applied $\sigma_{v}^{\prime}$ for samples of only-pellets and natural samples, compared to samples tested by [18].

3. the swelling index, $c_{s}$ is defined as the slope of the unloading-reloading section of the curves, and is found to be between 0.08 and 0.14 with an arithmetic mean of 0.11 for material above and within the crust;

4. for the pellets-only sample, $\sigma_{c}^{\prime}$ is $9 \mathrm{kPa} ; c_{c}$ approximates 1.34; and $c_{s}$ is found to be between 0.02 and 0.07 with an arithmetic mean of 0.04 .

Above the crust, the sediment exhibits a higher water content, with a more open structure. Pellets in this material are less well supported and therefore during one-dimensional compression, some will crush and resediment as clay, resulting in a reduction in the number of pellets. Based on the compression index values, crust material is less compressible than overlying material. Oedometer tests on natural and remoulded samples of similar material, ranging from $0.5 \mathrm{~m}$ to $18 \mathrm{~m}$ depth were completed by [20], measuring a $c_{c}$ of between 1.45 and 1.80 for natural noncrust samples and 1.20 for remoulded samples. The values obtained in the current investigation suggest that the crust material is less compressible than the material below the crust based on a comparison with [20]. The swelling index $\left(c_{s}\right)$ values measured for the sample taken from $0.03 \mathrm{~m}$ depth suggest that compression was irreversible up to $3 \mathrm{kPa}$, which is consistent with crushing of 
pellets and the gradual collapse of the natural fabric.

The ratio of $c_{s}$ to $c_{c}$ is approximately 0.1 for crust material and 0.06 for material above the crust. These values are consistent with clay material. [19] suggests that this ratio may be a "sensitivity indicator of fabric and inter-particle bonding in natural soil" ( [19], p356). The $c_{s} / c_{c}$ values are likely to be influenced by the bulk natural fabric of the crust, as well as variation in water content and specific fabric elements such as the percentage of pellets in a sample.

Figure 7 presents the information shown in Figure 6 on a normalised vertical axis of the void index $\left(I_{v}\right)$ following [19]. [18] found the intrinsic void ratio at $100 \mathrm{kPa}, e_{100}^{*}$ and coefficient of consolidation, $c_{c}^{*}$ for West African clays to be 2.13 and 1.03, respectively. A wide range of natural and remoulded, reconstituted clays were investigated by [19], which showed that most natural clays lay on a line approximately parallel to and above the intrinsic compression line (ICL) defined by the remoulded, reconstituted clays. An extension by [21] of [19] showed that a sensitivity framework could encompass the 'post-sedimentation'compression behaviour of natural clays. The clays examined by [19] are found to lie between sensitivities of 3 and 5 when interpreted using the framework proposed by [21]. The curves corresponding to various soil sensitivities for samples tested in this investigation are shown in Figure 7.

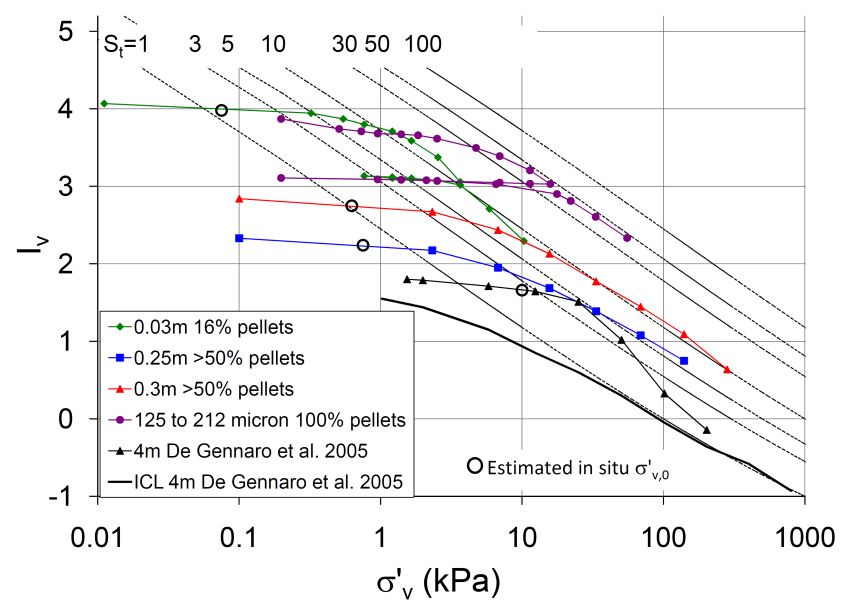

FIGURE 7: Void index $I_{v}$ plotted against the logarithm of applied $\sigma_{v}^{\prime}$ for samples of only-pellets and natural samples, compared to a sample from [18].

This figure indicates that the materials above, within and below the crust exhibit different sensitivity behaviour. The sample from $4 \mathrm{~m}$ approaches $S_{t}=5$ before dropping towards the ICL $\left(S_{t}=1\right)$ [18]. The sample from $0.03 \mathrm{~m}$ crosses $S_{t}=10$ before dropping below 10 and suggests a continuation towards the ICL with increasing stress level. The rate of reduction in $I_{v}$ is, however, much less than the sample from $4 \mathrm{~m}$ depth. This suggests that the natural structure of material above and below the crust is able to support a significantly higher vertical effective stress than a remoulded material before the structure begins to collapse under increasing stress. In contrast to both of these, the samples from crust material $(0.25 \mathrm{~m}$ and $0.3 \mathrm{~m}$ depth) tend to approach and then follow sensitivity curves defined by $S_{t}=5$ and $S_{t}=10$. The pelletonly sample exhibits extraordinary behaviour, remaining on $S_{t}$ of approximately 50. Its location, far above natural clays, is due to the large initial voids ratio produced by open, water-filled pores between individual pellets. The crust and pellet-only samples do not exhibit significant collapse of structure during onedimensional loading. This suggests that a unique normal consolidation line does not exist for clays starting with these structures; rather, a family of normal consolidation curves for such pelletrich samples may be developed. These observations also suggest that the crushing of pellets is not associated with loss of crustal stiffness, nor the demise of crustal strength.

\subsection{Faecal Pellet Percentages in Natural Samples}

Wet sieving of oedometer trimmings prior to testing, and of the consolidated sample after testing, was undertaken to provide quantitative information on the amount of pellet crushing caused by the tests. Figure 8 presents the results of the wet sieving. The following points are noted:

1. total pellet percentages of non-crust material from $0.03 \mathrm{~m}$ depth fell from $21 \%$ to $16 \%$ over a total stress change of $10 \mathrm{kPa}$;

2. the most significant reductions for non-crust material occurs for the $212 \mu \mathrm{m}$ to $300 \mu \mathrm{m}$ and $63 \mu \mathrm{m}$ to $125 \mu \mathrm{m}$ fractions;

3 . pellet percentages pre- and post- testing for crust material from $0.25 \mathrm{~m}$ and $0.3 \mathrm{~m}$ depth are comparable, with less than $4 \%$ variation in pellet percentage over a total stress change of $280 \mathrm{kPa}$; and

4. large reductions in pellet percentages are observed in fractions greater than $212 \mu \mathrm{m}$ for crust material, with a corresponding increase in material within the $63 \mu \mathrm{m}$ to $212 \mu \mathrm{m}$ fraction.

Within the crust, pellets are supported by adjacent pellets and an in-filling matrix of clay, which prevents pellets from excessive deformation and crushing. Nevertheless, larger pellets are more susceptible to crushing than smaller pellets, resulting in the reductions for pellets greater than $212 \mu \mathrm{m}$ in Figure 8 . The increase in material from $63 \mu \mathrm{m}$ to $212 \mu \mathrm{m}$ must be due to crushed pellet fragments. No faecal pellets were observed in the $4 \mathrm{~m}$-deep sample ( [18]), which is consistent with the observation that pellets only comprise about $15 \%$ of the total dry mass by about $2 \mathrm{~m}$ depth and the tendency for the $I_{v}-\sigma_{v}^{\prime}$ curve to approach the ICL. It is noted that the absence of a reference to pellets may only mean that they were not identified during the testing of samples. 


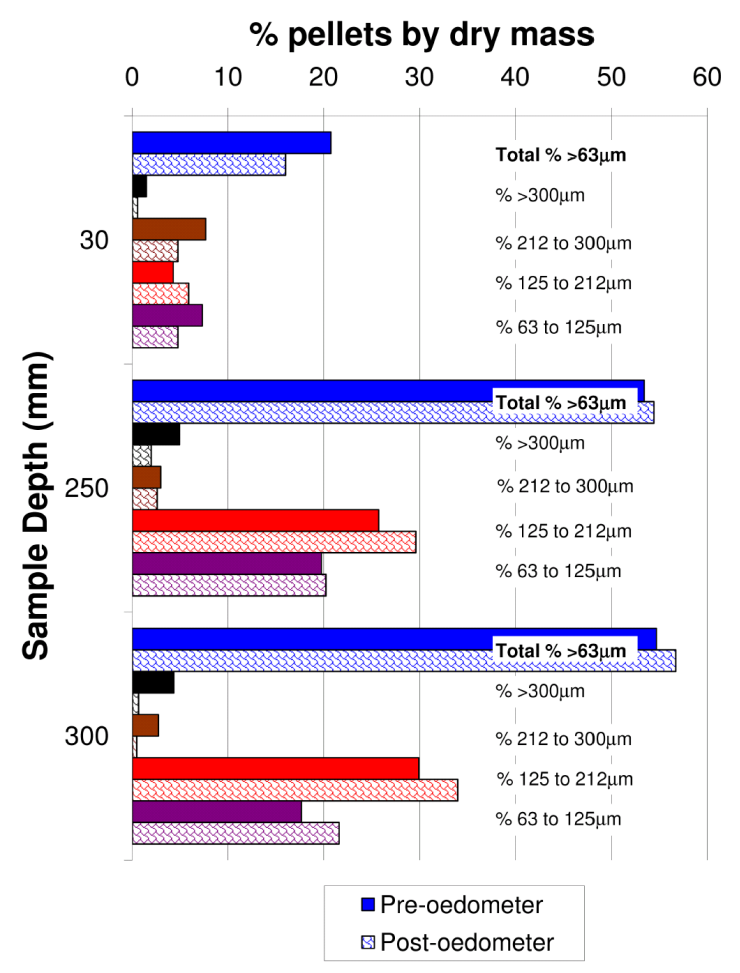

FIGURE 8: Comparison of faecal pellet percentages before and after oedometer tests for natural samples of depths $0.03 \mathrm{~m}, 0.25 \mathrm{~m}$ and $0.3 \mathrm{~m}$.

\subsection{Coefficient of Consolidation}

The coefficient of consolidation $\left(c_{v}\right)$ was determined following the procedure outlined in ASTM 2435. The general solution for determining the coefficient of consolidation is in terms of

$$
c_{v}=\frac{T_{v} d^{2}}{t},
$$

where $T_{v}$ is the dimensionless time factor; $d$ is the drainage distance assuming pore pressure dissipation through a unit cell; and $t$ is the time to reach the calculated proportion of primary compression completed. The dimensionless time factor, $T_{v}$, was determined using the square-root of time method (Taylor's Method), and interpolating the value for $T_{90}$, that is, the dimensionless time factor for $90 \%$ primary consolidation, and the corresponding time, $t$ to achieve this condition. The variation of $c_{v}$ with the cumulative vertical effective stress $\left(\sigma_{v}^{\prime}\right)$ applied by the oedometer for the natural and pellet-only samples is shown in Figure 9. Figure 10 presents $c_{v}$ plotted against the specific volume, $v$.

The following points are drawn from Figure 9:

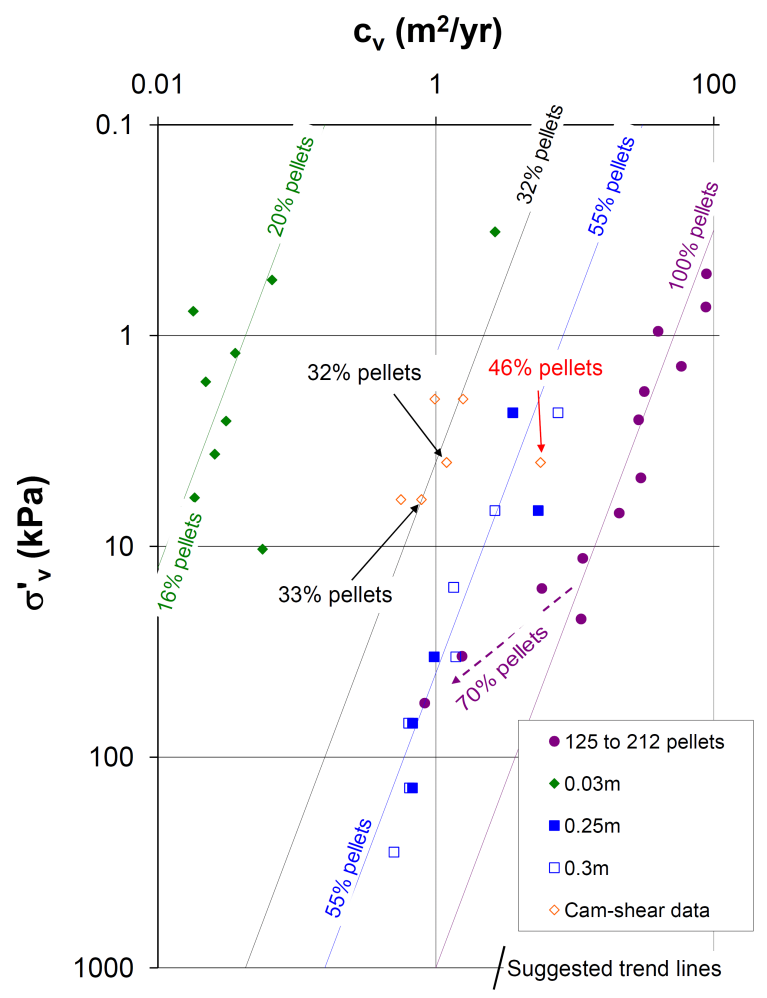

FIGURE 9: The coefficient of consolidation plotted against the applied $\sigma_{v}^{\prime}$ for samples of only-pellets and natural samples.

1. natural samples at different in situ vertical effective stresses exhibit significant variations in $c_{v}$ with increasing vertical effective stress;

2. samples at higher in situ vertical effective stresses (corresponding to crust material) exhibit $c_{v}$ values at least one order of magnitude higher than the sample at a lower in situ vertical effective stress; and

3. when compared to the literature, samples of crust material from $0.25 \mathrm{~m}$ and $0.3 \mathrm{~m}$ depth have significantly higher $\mathrm{c}_{v}$ values than would be expected for marine clays. For example, Singapore Marine Clay has $c_{v}$ of $0.5 \mathrm{~m}^{2} / \mathrm{yr}$ to $1.7 \mathrm{~m}^{2} / \mathrm{yr}$ ( [22]) and $0.47 \mathrm{~m}^{2} / \mathrm{yr}$ to $0.6 \mathrm{~m}^{2} / \mathrm{yr}$ ( [23]).

A series of curves are drawn in this figure, which relate the percentage of faecal pellets to the variation of the coefficient of consolidation at a particular vertical effective stress. It is shown that a sample containing $100 \%$ pellets (diameters $125 \mu \mathrm{m}$ to $212 \mu \mathrm{m}$ ) initially exhibits a $c_{v}$ of up to $100 \mathrm{~m}^{2} / \mathrm{yr}$. In contrast, a natural sample initially containing $20 \%$ pellets exhibits a $c_{v}$ four magnitudes smaller. Natural samples with faecal pellet percentages of $30 \%$ and $50 \%$ map intermediate parallel lines on the $\log \sigma_{v}^{\prime}-\log c_{v}$ plot in Figure 9. The coefficient of consolidation for the pellet-only sample is found to reduce by an order 


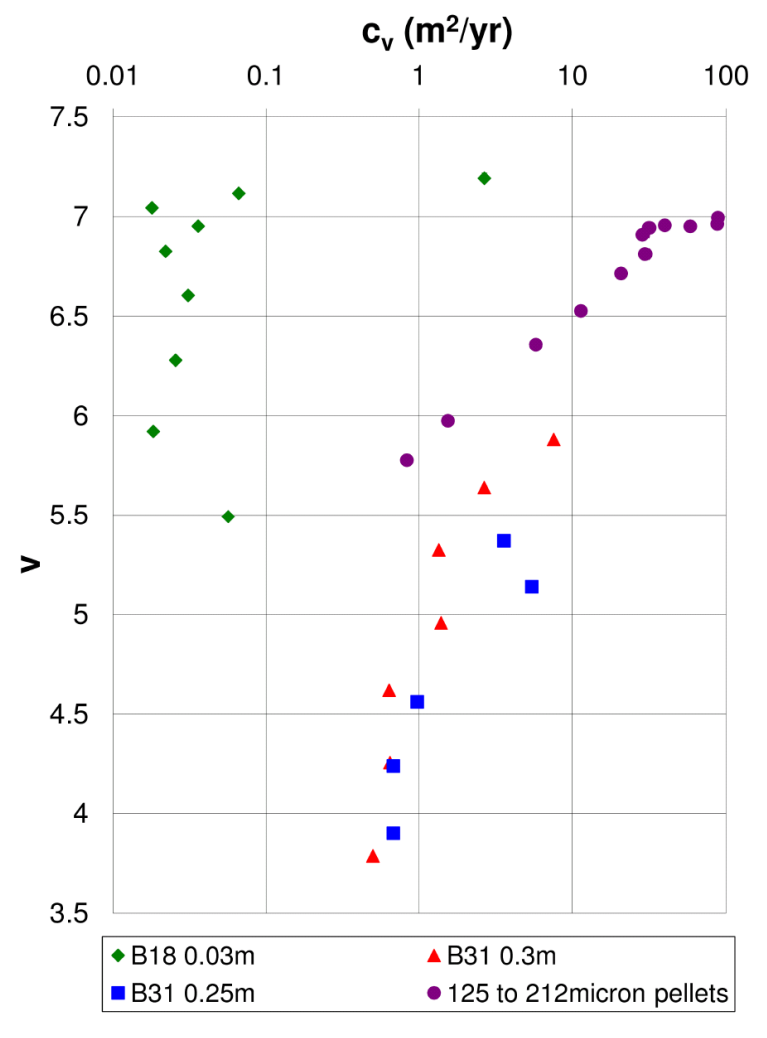

FIGURE 10: The coefficient of consolidation plotted against the specific volume for samples of only-pellets and natural samples.

of magnitude as the vertical effective stress rises from $20 \mathrm{kPa}$ to $40 \mathrm{kPa}$. This results in $c_{v}$ of the pellet-only material falling to values comparable with a natural sample containing over $50 \%$ pellets due to the fragmentation of pellets and the associated filling of void space. These observations are consistent with those made by [24] who considered the importance of soil fabric on soil properties. [24] noted the closure of open plant-root tubes due to increasing vertical effective stress, which caused a reduction in the coefficient of consolidation.

By plotting the coefficient of consolidation against the specific volume $v$ in Figure 10, it is shown that the pellet-only sample initially has $c_{v}$ values three orders of magnitude greater than the very shallow $(0.03 \mathrm{~m}$ depth) natural sample at a comparable voids ratio. The arrangement of open voids within these two samples is thus demonstrated to be significantly different. The pellet-only sample comprises compact pellets of clay surrounded with large macro-voids, thus allowing the dissipation of excess pore pressures to occur. The natural sample, by comparison, is an open clay matrix containing only a few compact pellets, and permeability is controlled by the matrix alone. A transitional zone may be present for the pellet-only sample and the natural samples containing over $50 \%$ pellets between specific volumes of
5.5 and 6. In this region, the percentage of pellets of the natural and pellet-only samples are within 15\%, and they may therefore exhibit similar mechanical properties.

\subsection{Variation in Permeability}

The variation in permeability, $k$, with respect to the onedimensional stiffness is shown in Figure 11. It is observed that the pellet-only sample tends towards the behaviour of the natural samples as the stiffness increases. The permeabilities of deeper samples are found to be higher than shallower, more compressible, samples that exhibit a more open fabric. Furthermore, it is observed that the relationship between the permeability and the one-dimensional stiffness of material containing over $50 \%$ pellets may be approximated by a power law. As noted from measuring the percentage of faecal pellets before and after compression, comparable numbers of pellets were present at both stages in these samples. The permeability, however, decreased by over two orders of magnitude. This suggests that the matrix of unpelletised clay surrounding pellets has compressed, and elastic deformation of the pellets and minor crushing has occurred. The initial permeability at low confining stress may represent drainage predominantly around pellets, facilitated by the open fabric of the matrix clay and open burrows. During onedimensional compression, the matrix fabric collapses, resulting in forced drainage through a mixture of both pellet material and compressed matrix clay, thus decreasing the permeability.

As expected, material containing fewer pellets exhibits lower permeabilities and lower one-dimensional stiffness. The pellet-only sample initially exhibits high, and relatively constant, permeability before dropping by two orders of magnitude towards the crust samples containing over 50\% pellets at comparable stiffness. This corresponds to the transitional zone between these samples, observed in Figure 9 and 10.

\section{Discussion on Physical Processes During Consoli- dation}

Based on the results of sample sieving before and after oedometer tests, it is not explicitly known when the majority of the pellet crushing occurs. During an oedometer test on 'conventional' soils, some crushing and rearrangement of particles occurs during initial loading. It is likely that a similar process occurs for the samples tested in this investigation. With increasing load, crushing occurs, initially of asperities and then of an increasingly larger proportion of particles (e.g. $[25,26])$. The $v-\sigma_{v}^{\prime}$ relationship will thus define the compression index, $c_{c}$. This interpretation of the mechanical behaviour during one-dimensional compression of the tested natural samples is likely to be a simplification of the actual process. The tested material consists of bioturbated material in the form of robust grains (pellets) within a highly compressible matrix, so during loading, two phases of 


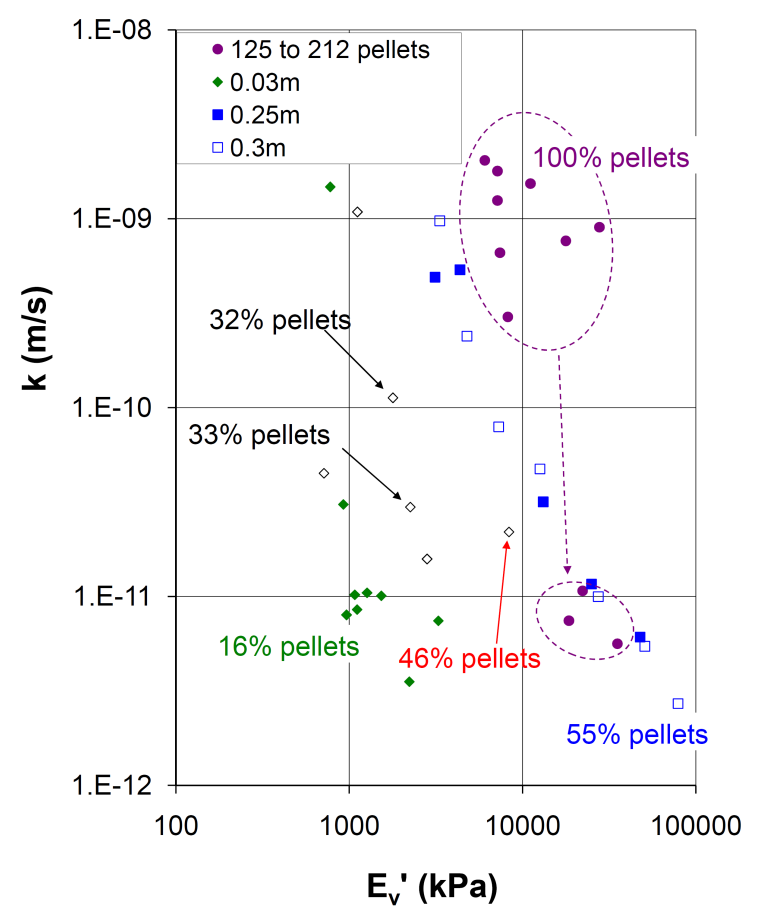

FIGURE 11: The permeability, $k$ plotted against the tangential one-dimensional stiffness, $E_{v}^{\prime}$ for samples of only-pellets and natural samples.

consolidation may occur concurrently, one of the matrix and the other of the pellets. Furthermore, the percentage of pellets will have an influence on whether the consolidation behaviour is dominated by pellets or the matrix. Initially, at low stress levels, the behaviour is likely to be dominated by the more compressible matrix. Robust pellets may be free to move within the matrix or, conversely, the matrix is free to flow round the pellets. As the stress level increases, deformation of poorly-supported pellets may contribute to the bulk consolidation characteristics, and some pellets may begin to crush. Finally, as the stress level reaches the crushing stress of individual grains, the proportion of clay matrix to grains increases due to resedimentation of the contents of crushed pellets. This stress level was not achieved in testing undertaken in this investigation as most pellets are still present after oedometer tests.

Stresses of over $280 \mathrm{kPa}$ during oedometer testing are reached in situ by sediments at over $100 \mathrm{~m}$ depth. As noted previously, at a depth of $1.9 \mathrm{~m}$, corresponding to material below the crust, the sediment contained only $15 \%$ faecal pellets by dry mass (see Figure 2). It is impossible to believe that the species of invertebrates responsible for faecal pellets in recent, shallow sediments were not also acting in sediments tens of thousands of years ago, which are now more deeply buried and found to be relatively free of pellets. The observation that only a minimal change occurs in the number of pellets present in crustal samples loaded to high stresses, demonstrates that increasing overburden stress is not, on its own, the cause of pellet destruction, nor of loss of crustal strength.

\section{Implications for Hot-Oil Pipelines}

The current practice of undertaking a particle size distribution on core samples following standards such as ASTM D44263 will result in a significantly skewed interpretation of the grain size. This is due to the remoulding and destroying of all natural fabric prior to the analysis, resulting in a PSD-interpreted clay. If faecal pellets formed during invertebrate bioturbation were structurally weak, they might be expected to crush under pipe stresses. However, faecal pellets exhibit significant robustness, and will modify the grain size distribution and the soil properties with the degree of modification depending on their size and abundance.

It is therefore concluded that the wet sieving of marine sediments, preferably to $20 \mu \mathrm{m}$, should be routinely undertaken to provide an accurate indication of the natural sediment's grain size distribution. Design charts similar to that shown in Figure 12 will be useful to pipeline designers by aiding in the interpretation of interface shear tests and by providing information on the consolidation behaviour of natural samples under pipeline loads.

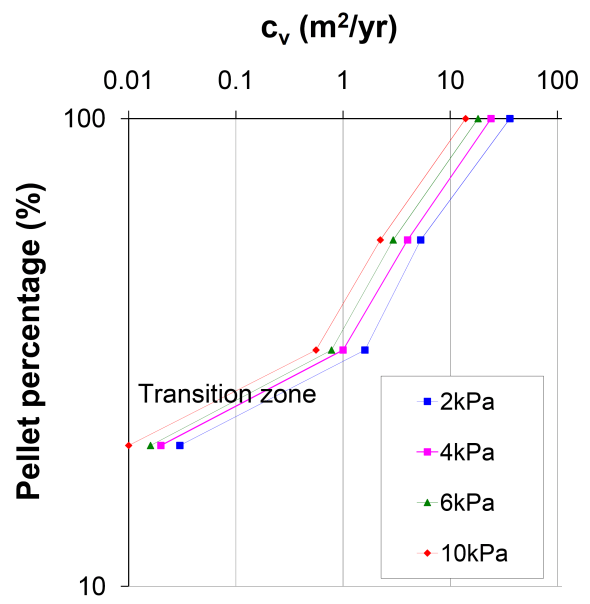

FIGURE 12: Empirical design chart showing the relationship between the percentage of pellets to the coefficient of consolidation.

The $c_{v}$ values shown in this figure implicitly account for crushing of pellets under the applied pipeline stress and therefore it is only necessary to measure the natural material's initial pellet 
percentage. It is observed that a dramatic decrease in the coefficient of consolidation occurs when the pellet percentage drops below $30 \%$. This may coincide with a transition zone, where the behaviour of the natural soils move from being dominated by pellets to being dominated by the clay matrix. These results are key to understanding the behaviour of hot pipelines installed into these highly variable and complicated sediments.

\section{ACKNOWLEDGMENT}

The authors would like to express their grateful thanks to BP Exploration for the provision of core samples used in this research.

\section{REFERENCES}

[1] Kuo, M. Y.-H., and Bolton, M. D., 2009. "Soil characterisation of deep sea West African clays: is biology a source of mechanical strength?". In 18th ISOPE, Osaka.

[2] Kuo, M. Y.-H., and Bolton, M. D., 2010. "New evidence for the origin and behaviour of deep ocean "crusts", In ISFOG II, S. Gourvenec and D. J. White, eds., Taylor \& Francis Group, London.

[3] Kuo, M. Y.-H., 2011. "Deep ocean clay crusts: behaviour and biological origin". $\mathrm{PhD}$ thesis, University of Cambridge.

[4] Ehlers, C. J., Chen, J., Roberts, H. H., and Lee, Y. C., 2005. "The origin of near-seafloor crust zones in deepwater". In ISFOG, S. Gourvenec and M. Cassidy, eds., Taylor \& Francis Group, London.

[5] Rhoads, D., and Boyer, L., 1982. The effects of marine benthos on physical properties of sediments: a successional perspective. Plenum Geobiology Series. Plenum Press, New York.

[6] Aller, R., 1982. The effects of macrobenthos on chemical properties of marine sediment and overlying water. Animal Sediment Relations. Plenum Press, New York.

[7] Meadows, A., and Meadows, P. S., 1994. "Bioturbation in deep-sea pacific sediments". Journal of the Geological Society, 151, pp. 361-375.

[8] Murray, J. M. H., Meadows, A., and Meadows, P. S., 2002. "Biogeomorphological implications of microscale interactions between sediment geotechnics and marine benthos: a review". Geomorphology, 47, pp. 15-30.

[9] Moore, H., 1931. "The specific identification of faecal pellets". Journal of the Marine Biology Association, New Series, $\boldsymbol{X V I I}(2)$.

[10] Moore, H., 1931. "The muds of the clyde sea area. iii. chemical and physical conditions; rate and nature of sedimentation; and fauna". Journal of the Marine Biological Association, New Series, XVIII(2).

[11] Meadows, P. S., Reichelt, A. C., Meadows, A., and Water- worth, J. S., 1994. "Microbial and meifaunal abundance, redox potential, ph and shear strength profiles in deep sea pacific sediments". Journal of the Geological Society, 151, pp. 377-390.

[12] Baltzer, A., Cochonat, P., and Piper, D. J. W., 1994. "In situ geotechnical characterisation of sediments on the Nova Scotian Slope, eastern Canadian continental margin”. Marine Geology, 120(7), pp. 291-308.

[13] Grupe, B., Becker, H., and Oebius, H., 2001. "Geotechnical and sedimentological investigations of deep-sea sediments from a manganese nodule field of the Peru Basin". DeepSea Research Part II, 48, pp. 3593-3608.

[14] Meadows, P. S., and Tait, J., 1989. "Modification of sediment permeability and shear-strength by 2 burrowing invertebrates". Marine Biology, 101(1), pp. 75-82.

[15] Jones, S. E., and Jago, F. C., 1993. "In situ assessment of modification of sediment properties by burrowing invertebrates". Marine Biology, 115, p. 10.

[16] Shirley, D. J., 1978. "An improved shear wave transducer". Journal of the Acoustical Society of America, 63(5).

[17] Rowden, A. A., Jago, F. C., and Jones, S. E., 1998. "Influenc of benthic macrofauna on the geotechnical and geophysical properties of surficial sediment, North Sea". Continental Shelf Research, 18, pp. 1347-1363.

[18] De Gennaro, V., Delage, P., and Puech, A., 2005. "On the compressibility of deepwater sediments of the Gulf of Guinea”. In ISFOG, S. Gourvenec and M. Cassidy, eds., Taylor and Francis Group, London, pp. 1063-1069.

[19] Burland, J., 1990. "On the compressibility and shear strength of natural clays". Geotechnique, 40(3), pp. 329378.

[20] Le, M. H., 2008. "Caracterisation physique et mecanique des soils marins d'offshore profond". PhD thesis, l'Institut Français du Pétrole et le CERMES (Institut Navier).

[21] Cotecchia, F., and Chandler, R. J., 2000. "A general framework for the mechanical behaviour of clays". Geotechnique, 50(4), pp. 431-447.

[22] Chu, J., Bo, M. W., Chang, M. F., and Choa, V., 2002. "Consolidation and permeability properties of Singapore Marine Clay". Journal of Geotechnical and Geoenvironmental Engineering, ASCE, 128(9), pp. 724-732.

[23] Arulrajah, A., and Bo, M. W., 2008. "Characteristics of Singapore Marine Clay at Changi”. Journal of Geotechnical and Geological Engineering, 26, pp. 431-441.

[24] Rowe, P. W., 1972. "The relevance of soil fabric to site investigation practice”. Geotechnique, 22(2), pp. 195-300.

[25] McDowell, G., and Bolton, M. D., 1998. "On the micromechanics of crushable aggregates". Geotechnique, 48(5), pp. 667-679.

[26] Bolton, M. D., Nakata, Y., and Cheng, Y. P., 2008. "Microand macro-mechanical behaviour of DEM crushable materials". Geotechnique, 58(6), pp. 471-480. 